\title{
Rain attenuation in broadband satellite service and worst month analysis
}

\author{
Idrissa Abubakar ${ }^{1}$, Jafri Bin Din ${ }^{2}$, Lam Hong Yin ${ }^{3}$ Manhal Alhilali ${ }^{4}$ \\ ${ }^{1,2,4}$ Wireless Communications Centre, School of Electrical Engineering, Universiti Teknologi Malaysia, Malaysia \\ ${ }^{3}$ Department of Electrical Engineering Technology, Faculty of Engineering Technology, \\ Universiti Tun Hussein Onn Malaysia, Malaysia \\ ${ }^{1}$ Satellite Control \& Network Operations, Nigerian Communication Satellite Ltd, Nigeria
}

\begin{tabular}{l}
\hline Article Info \\
\hline Article history: \\
Received Jan 15, 2019 \\
Revised Apr 1, 2019 \\
Accepted May 3, 2019 \\
\hline
\end{tabular}

Keywords:

ACM

Broadband signal

PIMT

Rain attenuation

Worst month

\begin{abstract}
Satellite link design, link margin and services at lower bands of satellite spectrum has been facing the challenges of meeting the demands for higher bandwidth requirements. Satellite operators and service providers are been compelled to migrate to the use of higher frequencies above $10 \mathrm{GHz}$. These higher frequencies were discovered to be vulnerable to atmospheric degradation creating the challenge of service availability especially for tropical rain zones with higher rainfall intensities and longer rain event durations. This study strive to evaluate the profile of rainfall and the monthly and annual variability to improve the design parameters of satellite propagation. Two yeas rainfall measurement campaign was conducted in Abuja at Nigcomsat-1R ground station with a view to understanding the characteristics of Abuja rain. The location of the site is on lat. 9.06o $\mathrm{N}$ and lon. 7.48o E. Tipping bucket rain gauge was used for point rain rate and 1.8 $m$ VSAT antenna was installed to monitor the rain induced attenuation on satellite broadband signal. The results shows a huge variability between month to month as well as annual average between 2016 and 2017. The performance of broadband satellite service was found to largely to depend on the quality of the carrier power above the system noise rather than bandwidth capacity or the receive signal level while higher attenuations are associated with higher rain intensities and the slant path effects.
\end{abstract}

Copyright $@ 2019$ Institute of Advanced Engineering and Science. All rights reserved.

\section{Corresponding Author:}

Prof. Dr. Jafri Bin Din

Wireless Communications Centre, School of Electrical Engineering,

Universiti Teknologi Malaysia,

81310 Johor Bahru, Malaysia.

Email: jafri@utm.my

\section{INTRODUCTION}

Satellite communications operating and proving services at high frequencies above $10 \mathrm{GHz}$ are expected to deliver a comprehensive high capacity and higher data rate for broadband and multimedia services. Such services are disposed to atmospheric impairments essentially the rain effects. This singular impairment is even worse in the tropical and equatorial regions characterized by heavy precipitation especially for VSAT services [1]. Abuja Nigeria is geographically located in the tropical region on latitude 9.06o $\mathrm{N}$ and longitude 7.48o E. Rain attenuation and link outages is a predominant challenges for satellite service for both direct to home (DTH) television or broadband internet service [2]. Satellite communication system operates on the principle of point to point and point to multipoint, with clear view from all form of obstructions including cloud, rain and tall vegetation cover. This is called clear line-of-sight (LOS) between the transmitting and receiving terminal of the communicating network [3]. The communication structure in broadband service uses a very small aperture terminal (VSAT) in two-way (duplex) transmission system via 
satellite link. Functioning as a point to point or point to multipoint networks via a fixed satellite service (FSS), to provide a number of advantages. These advantages are especially more for difficult and mountainous terrain, Islands, high sea explorations and the unwired locations for rapid response including disaster management [4].

This study in its quest to evaluate the level of rain induced attenuation on Nigcomsat-1R satellite broadband service, employs the use tipping bucket rain gauge to conduct 2 years experimental measurement campaign to quantify the point rainfall rate (R0.01) at Abuja ground station of Nigcomsat-1R. Employes the use VSAT to evaluate the effects of rain induced attenuation on broadband service to provide a design and performance threshold for future satellite projects. A satellite link is said to be available when the ratio of time of connectivity is stable for use with a carrier-to-noise ratio above a defined threshold specified for a chosen bit error rate of performance. The outage time also called fade duration is a percentage of time for which the desired error of performance or threshold could not be realize and subsequently the signal is lost as it becomes similar to system noise. International telecommunication union (ITU-R) has made some recommendations to evaluate some of these atmospheric effects affecting satellite to earth propagation [3]. These recommendations are (ITU-R.P.618) for rain attenuation, (ITU-R.P.837) for rain rate distributions, (ITUR-838) for specific attenuation on the space to earth and (ITU-R P.839) for rain height as well as fade dynamics among others. Precipitation within the troposphere are generally classified as either liquid, solid or transition between liquid and solid segments especially the melting ice layer [5]. The liquid precipitation include rain and drizzle with varying the degree of intensity. Rainfall intensity is classified according to the rate of precipitation, which depends on the considered time and location [6]. Some meteorological agencies considered precipitation as light when the rate is less than $2.5 \mathrm{~mm} / \mathrm{h}$ and moderate for the rain rate is between $2.5 \mathrm{~mm} / \mathrm{h}$ and $7.6 \mathrm{~mm} / \mathrm{h}$. while heavy when the rate is between $10 \mathrm{~mm} / \mathrm{h}$ and $50 \mathrm{~mm} / \mathrm{h}$. Precipitation above $50 \mathrm{~mm} / \mathrm{h}$ is considered violent rainfall intensity [7]. Recent studies have shown that for bi-seasonal tropical locations, the ZDI tends to be higher during wet season compared to the dry season thereby increasing the level of induced attenuation on the satellite to earth links due to increase in the slant path to the satellite [1].

To achieve a good Quality of Service (QoS) and reliable signal availability for both down link and uplink transmission, a deliberate provision is required to mitigate the attenuation due to rain effects at higher frequency bands [3]. To quantify the link loss along the slant path as well as the total signal fade effect especially for broadband services providing mission critical assignment, emergency response, financial and security information management, telemedicine services and control towers will require an instantaneous switching system to drive the mitigation control system. Satellite radio link designers have been utilizing one minute integration time (1-min) for statistical characterization of rain rates distributions and conversions of long term and worst-month statistics [8]. The concept of "worst month" in accordance with (ITU-R P.581-2) recommends, that performance criteria for radio communication systems often refer to "any month" as the period of reference. The design of such systems requires the statistics of propagation effect relevant to the period of reference of the performance criteria and the need for an unambiguous definition for the period of reference. That the fraction of time during which a preselected threshold is exceeded in the worst month of a year is referred to as the annual worst-month time fraction of excess. That the statistic relevant for the performance criteria referring to "any month" is the long-term average of the annual worst-month time fraction of excess. The worst month of a year for a preselected threshold for any performance degrading mechanism, be that month in a period of twelve consecutive calendar months, during which the threshold is exceeded for the longest time. The worst month is not necessarily the same month for all threshold levels (ITU-R P.581-2). Further studies in the review work shows wider inconsistencies of ITU-R recommended prediction method was observed to have underestimated the values of rainfall rate at $0.01 \%$ of time by $52.8 \%$ while overestimated for $0.001 \%$ of time exceedance with $7.6 \%$ Sumatra from an optical rain gauge measurement. These studies in general terms are in agreement with the measurements compared to prediction of rain induced attenuation on satellite link [9].

The overall performance of satellite communication network is generally presented in terms of carrier power above the noise level. The carrier to noise ratio $(\mathrm{C} / \mathrm{N})$ of any radio frequency $(\mathrm{RF})$ signal and the bit energy to noise density $(\mathrm{Eb} / \mathrm{No})$ for digital system are important performance parameters to consider for optimal data rate [10]. Studies have shown that link availability above the threshold is critical for quality of service in terms carrier power above the system noise level [11]. Satellites operating above $10 \mathrm{GHz}$ are generally vulnerable to rain induced attenuation hence will require a measurement approach to improve the design parameters. This is because predicted values for link margin has not performed optimally in tropical regions to compensate for the rain effect [12]. Higher rain rate is associated with higher signal attenuation, therefore defines the level of attenuation and link margin. Underestimation of rain rate will affect the link availability while over estimation attract higher cost [13]. The instances of rain height leading to higher losses along the slant path of satellite link due to climate change, the random variations in rain height and the annual variability in the overall rain profile will somehow undermine the prediction parameters [14]. 
Therefore measurements campaign and designing for real-time propagation impairment mitigation technique (PIMT) can provide alternative to underestimations of link margin.

\section{RESEARCH METHOD}

The most reliable and appropriate method of reducing the probability of link outage and to improve the link availability during rain event for any satellite communications services is to provide for adequate link margin and effective PIMTs operating in real-time events [15]. A reliable choice of PIMT can only be determine with the knowledge of local precipitation characteristics. A tipping bucket rain gauge and VSAT receiving terminal were employed for this measurement campaign. The tipping bucket rain gauge depicted in Figure 1 was installed on the rooftop of Nigcomsat-1R network operations building. This is to avoid any obstruction or blockage that might affect the measurements. The second but parallel measurement setup was the satellite receiving station.

The VSAT was used to access internet service via satellite (Nigcomsat-1R) link, operate in duplex mode for both uplink and downlink on forward and return channel as communication path between the remote and the gateway data center called the hub. The access to the hub is based on time division multiple access (TDMA) network using time slot for multiple channel per carrier (MCPC). This is because the VSAT is part of the general broadband network sharing the bandwidth with other users within the network cluster to achieve high throughput [14]. The tipping bucket rain gauge is a meteorological device that measures the amount of precipitation with event time stamped. The rain tips counting was recorded base of the bucket capacity emptying after collecting the maximum capacity of water. The system contains 2 alternating bucket controlled in position by a pivot and lever. The lever dumps the collected water and sending a pulse to a data logger for record counting in real time of the day. The rain gauge parameters is presented in Table 1. Figure 1 and Figure 2 shows the schematic of the rain gauge and the VSATs in clear sky and rain induced link attenuation, while the empirical measurements of rain induced effect is presented in Figure 8 and Figure 9 as measured using spectrum analyzer.

Table 1. The Tipping Bucket Rain Gauge Specifications

\begin{tabular}{ccccc}
\hline Tipping Bucket Parameters & Values & Units & VSAT Parameters & Values \\
\hline Calibration Accuracy & $\pm 1.0 \%$ & $\mathrm{~mm} / \mathrm{h}$ & Type & offset \\
Maximum Rain Rate & 12.7 & $\mathrm{~cm} / \mathrm{h}$ & Diameter & $1.8 \mathrm{~m}$ \\
Resolution & $0.2(\mathrm{RG} 3-\mathrm{M})$ & $\mathrm{mm}$ & Frequency & $12.6244 \mathrm{GHz}$ \\
Temperature Range & $0^{\circ}$ to +50 & ${ }^{\circ} \mathrm{C}$ & Polarization & Vertical \\
Storage temperature & $-20^{\circ}$ to +70 & ${ }^{\circ} \mathrm{C}$ & Elevation Angle & 47.83 \\
Housing Aluminum & 15.24 & $\mathrm{~cm}$ & Latitude & $9.06 \mathrm{E}$ \\
Orifice diameter & 15.39 & $\mathrm{~cm}$ & Longitude & $7.48 \mathrm{~N}$ \\
Weight & 1.2 & $\mathrm{Kg}$ & Altitude & $334 \mathrm{~m}$ \\
\hline
\end{tabular}

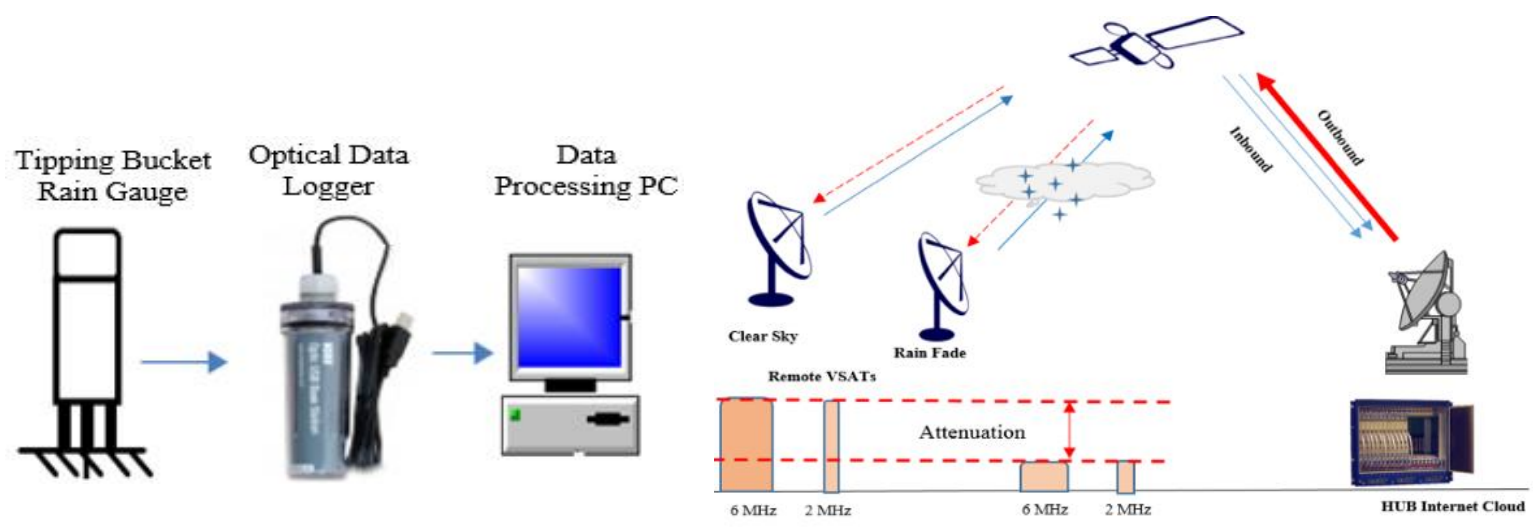

Figure 1. Schematic of Rain gauge data access and Storage system

Figure 2. Receive Signal level in Rain Attenuation

It is widely recognized that rain rate distribution at $0.01 \%$ of time is particularly important to the estimation of rain attenuation statistics [16]. The accuracy of rain rate distribution strongly depends on data processing method [17]. For propagation purposes, the best accuracy is obtained when the data logger records the tip instance with a resolution of at least one second. The bucket capacity $\mathrm{C}(\mathrm{mm})$, the time 
separation $\mathrm{T}$ ( $\mathrm{sec}$ ) between two consecutive tips and the number of tips in every minute of rain event. To investigate the performance of broadband internet utilization in relation to the allocated bandwidth $2 \mathrm{MHz}$ and $6 \mathrm{MHz}$ capacity were secured and the observations were concurrently recorded. The measurements were considered under the same condition of carrier to noise ratio, other carrier parameters including modulation and forward error correction coding rate. The VSATs and rain gauge were installed at the same location on latitude $9.06^{\circ} \mathrm{N}$ and longitude $7.48^{\circ} \mathrm{E}$ at NigComSat ground station. When considering the effect of rain attenuation of broadband satellite service, it is more important to deduce the instantaneous rain rate for feedback and acknowledgement of event to implement an event dependant PIMT especially for adaptive coding and modulation scheme. Therefore it is necessary to determine the instantaneous rain rate. The general relation for $\left(\mathrm{R}_{0.01}\right)$ is given by:

$$
R=3600 \frac{C}{T}
$$

$C$ : rain gauge bucket capacity $(0.2)$ and

$T$ : time period in second for 1 event

The processing of the rain tips includes the time interval between two consecutive drops. If the time interval between two tips is shorter than two seconds for the rain intensity greater than $360 \mathrm{~mm} / \mathrm{h}$, the second tip is not considered as it is likely due to bucket bounce. If the rain event is starting with two tips separated by a time interval shorter than 1-hour, the first of the two tips is not considered. Considering two tips in the same event, constant rain intensity is assigned to the period between the two tips. From Equation $1, C=0.2$ $\mathrm{mm}$ and $T$ is the separation in seconds between the two consecutive tips. The rain intensity at each minute will be equal to the average rain rate for the minute under observation. The instantaneous rain rate Model can then be derived from:

$$
R\left(x_{i+1}-x_{i}\right)=\frac{\Delta v}{\left(x_{i+1}-x_{i}\right)}
$$

$R\left(x_{i+1}-x_{i}\right)=$ the instantaneous rain rate during two consecutive tip minutes, $x i$ and $x_{i+1}$, for $i=1,2, \ldots, n-1$. $(\mathrm{n}=$ total number of tip per minutes) while $\Delta v$ is the rain gauge bucket size $(0.2 \mathrm{~mm})$.

$$
\mathrm{Ri}=\mathrm{R}(\mathrm{xi}+1-\mathrm{xi}) / \mathrm{T}
$$

\section{RESULTS AND ANALYSIS}

The discussion and result obtained from measurements campaign to quantify the rain rate at Abuja ground station of NigComSat-1R using rain gauge. Rainfall data obtained from the rain gauge was processed to generate the rain rate time series. The performance of average worst month (AWM) and average year (AY). The annual variation between the monthly rain rate of 2016 and 2017 were presented and discussed. Comparison between average annual rain rate of 2016 and 2017 were presented with that of ITUR-P837-7 prediction.

The performance of satellite broadband signal collected from two VSATs with allocated bandwidth capacity of $2 \mathrm{MHz}$ and $6 \mathrm{MHz}$ were presented in this chapter. The allocated bandwidth capacity adopted for this study is based on shared transponder with other VSATs. The rainfall data processing was done in Matlab program to generate the time series of rain rate.

\subsection{Statistics of Rainfall for Average Year and Average Worst Month}

The accuracy of rain rate distribution can be influenced by the data processing tool employed, hence the use of Matlab software for processing as a universal tool. Most accurate measurements can be obtained when the rain gauge data logger records the rain tipping time which can then be averaged over one minute. Table 2 presents a sample of the rain tips count showing gradual increments in the count as the intensity increases with time of the day.

The cummulative statistics of an average year (AY) and average worst month (AWM) of measurements the 2016 and 2017 rainfall records were presented in Figure 3 and Figure 4. The average monthly accumulated rainfall in millimeter $(\mathrm{mm})$ for the period of measurement shows a considerable variations between the rain regimes of 2016 and that of 2017 respectively. The month of June recorded the highest accumulation volume of $263 \mathrm{~mm}$ in 2016 while the month of August recorded the highest volume of $334 \mathrm{~mm}$ in 2017 and the highest of the 2 years measurements period from January 2016 to December 2017. 
The histogram of monthly accumulation of rainfall show a peak similarity between the month of June in 2016 and August for the year 2017, with more rainfall occurrences and the total time count in minutes. A double peak was recorded in 2017 while a single-peak rainfall patterns was observed in 2016 characterizing the tropical climates with the July 2017 discontinuity. Nevertheless, the annual variability between 2016 and 2017 was very enormous. The rainfall accumulation during the July discontinuity in 2017 and the all-time peak rainfall resuming in August 2017, recorded the highest accumulation during the two years measurements period. The observed variability in 2017 from the double-peak variance was $136 \mathrm{~mm}$ between June and July of the first peak. A cummulative variance of $154 \mathrm{~mm}$ was also recorded between July and August of 2017 in the second-peak rainfall volume. This anomaly may be attributed climate change effect which could impact on the worst month statistics for link design and link margin in satellite communication systems.

Table 2 Tipping Bucket Recorded Rain Event Sample

\begin{tabular}{ccccc}
\hline $\begin{array}{c}\text { Rain event date and } \\
\text { time }\end{array}$ & $\begin{array}{c}\text { Cummulative } \\
\text { Rain Tips Count }\end{array}$ & $\begin{array}{c}\text { 1 Min Time } \\
\text { Interval }\end{array}$ & $\begin{array}{c}\text { Time difference } \\
\text { between 2- tips drops }\end{array}$ & $\begin{array}{c}\text { Accumulated Rain } \\
\text { water in 1-Min }\end{array}$ \\
\hline 05/19/16 01:18:08 PM & 2.0 & & 16 & \\
05/19/16 01:18:21 PM & 2.2 & & 13 & \\
05/19/16 01:18:37 PM & 2.4 & 1 Min & 16 & $0.8 \mathrm{~mm}$ \\
05/19/16 01:18:49 PM & 2.6 & & 12 & \\
05/19/16 01:19:04 PM & 2.8 & & 15 & \\
05/19/16 01:19:14 PM & 3.0 & & 12 & \\
05/19/16 01:19:26 PM & 3.2 & 1 Min & 12 & \\
05/19/16 01:19:38 PM & 3.4 & & 12 & \\
05/19/16 01:19:50 PM & 3.6 & & 9 & \\
05/19/16 01:19:59 PM & 3.8 & & 10 & \\
05/19/16 01:20:09 PM & 4.0 & & 10 & \\
05/19/16 01:20:17 PM & 4.2 & & 5 & \\
05/19/16 01:20:27 PM & 4.4 & & 2 & \\
05/19/16 01:20:32 PM & 4.6 & & 9 & \\
05/19/16 01:20:34 PM & 4.6 & 1 Min & 8 & \\
05/19/16 01:20:43 PM & 4.8 & & 2 & \\
05/19/16 01:20:51 PM & 5.0 & & & \\
05/19/16 01:20:52 PM & 5.2 & & & \\
\hline
\end{tabular}

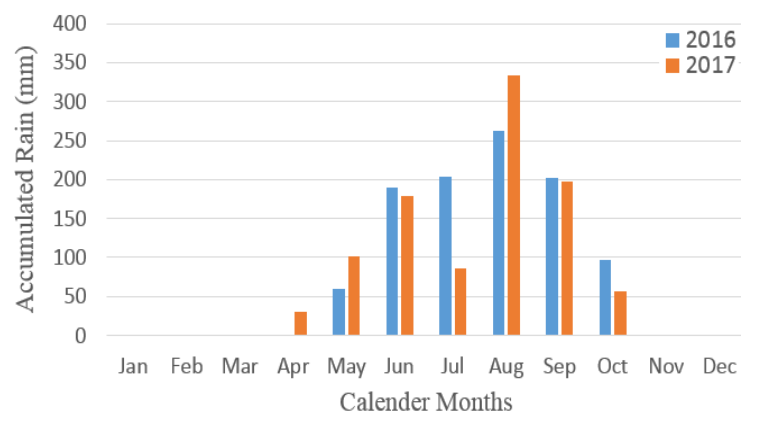

Figure 3. Monthly Accumulation of Rainfall distribution for 2016 and 2017

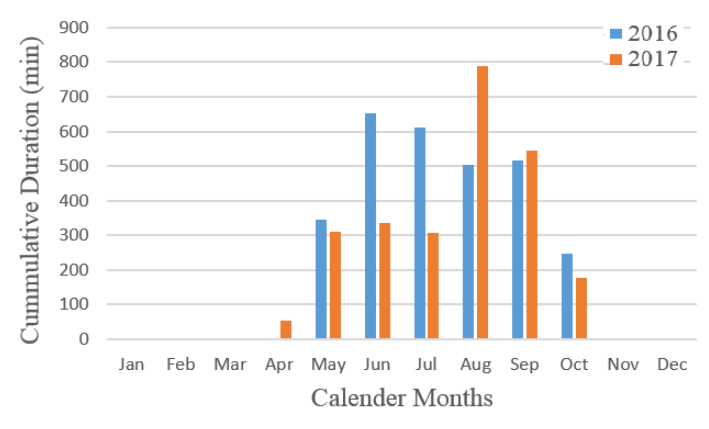

Figure 4. Monthly Cumulative Event Duration in minutes for 2016 and 2017

The "worst months" rain rate scenarios in Abuja is presented in Figure 5 and Figure 6 for 2016 and 2017 respectively. The year 2016 identified three months as high intensity rain months. These are the months of June, August and September which could be considered on the average as the worst months in 2016 having the rain rate above $100 \mathrm{~mm} / \mathrm{h}$ at $0.01 \%$. The months of May, July and October recorded a moderately high rain rate above $80 \mathrm{~mm} / \mathrm{h}$ at $0.01 \%$ while June is uniquely all time high even for $0.1 \%$ and $0.001 \%$ in 2016. The average rain rate distributions for all the calendar months of 2016 representing the value for the average year (AY) is labelled (2016) in Figure 5 and for the year (2017) in Figure 6. Convincingly the month of June 2016 clearly shows the highest value of rain rate at $0.01 \%$ of time exceedance and the cummulative of event duration. However at $0.1 \%$ all the calendar months exhibit the rain rate to be above $50 \mathrm{~mm} / \mathrm{h}$ in Figure 5. The average rain rate distributions for all the calendar months of 2016 representing the value for the average year (AY) is labelled (2017) in Figure 6 presents a total departure from 2016 for both monthly 
variation and average year. The annual average rainfall intensity at $0.01 \%$ shows the presence of heavy rain rate which can greatly impact on broadband satellite link availability.

The year 2017 measurements campaign starting from January to December 2017, identified two months of August and September as high intensity rainfall months. Figure 6 shows the months of August and September as the high intensity rainfall months with August observed to be the worst months for 2017 at $0.01 \%$ having the rain rate above $120 \mathrm{~mm} / \mathrm{h}$. The annual average recorded higher value in 2017 when compared to the preceding year of 2016 recording $80 \mathrm{~mm} / \mathrm{h}$ at $0.01 \%$. The average rain rate distributions for all the calendar months of 2017 representing the value for the average year labelled (2017) in Figure 6 showing an average of $100 \mathrm{~mm} / \mathrm{h}$. The 2017 month-to-month rain intensity shows a very wide variation except for the month of May that was in close agreement with the annual average year having rain rate of 100 $\mathrm{mm} / \mathrm{h}$ at $0.01 \%$. On the overall observation between Figure 5 and Figure 6 there was a huge variation between the measurements of 2016 and 2017. This significant difference can greatly influence the quality of satellite services in general.

\section{Annual Rainfall Distribution of 2016 and 2017}

Figure 7 presents the comparison of prediction and annual rainfall rate of two years measurements at NigComSat ground station in Abuja for the period starting from January 2016 to December 2017. The measurement results for annual averages for 2016 and 2017 were both observed to be in disagreement with ITU-R P. 837-7. Showing the ITU-R P. 837-7 to have underestimated the rain rate at $0.01 \%$ for the location of Abuja Nigeria. The climate of Abuja is characterized by the tropical effects and is being influenced by the increasing month to month random variations as shown between the records of 2016 and 2017 results. The difference between the measured rain rate and the ITU-R has shown to be very significant difference at $0.01 \%$. Such result can be said to ratify the location of measurement is a tropical rain zone as shown in the ITU-R global rain map. The influence of local climate is greatly influencing the performance of both direct broadcast and broadband services in Abuja, hence the motivation for this study. While ITU-R P. 837-7 shows $75 \mathrm{~mm} / \mathrm{h} 2016$ recorded $85 \mathrm{~mm} / \mathrm{h}$ while the 2017 shows $100 \mathrm{~mm} / \mathrm{h}$.

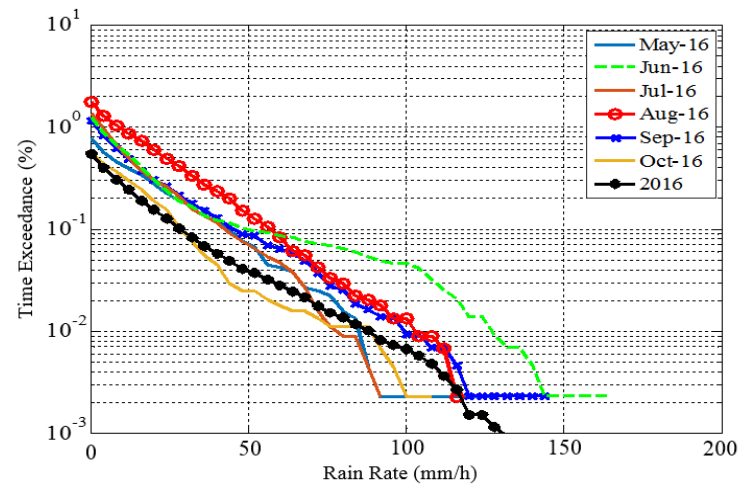

Figure 5. Monthly Variability and Worst month distribution for 2016 Rain rate Measurements

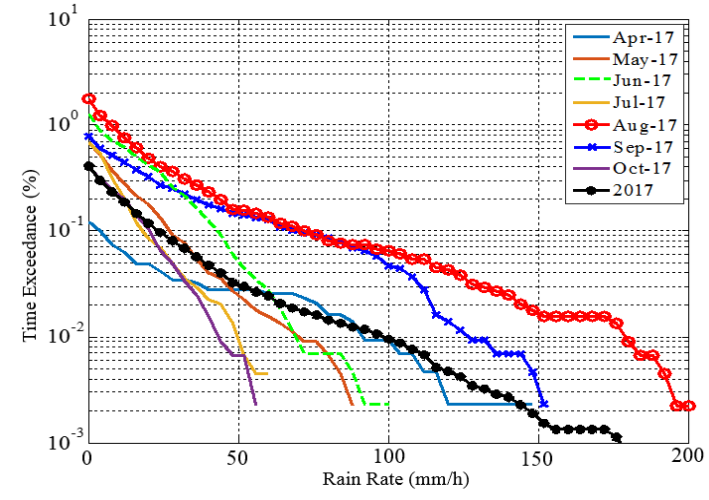

Figure 6. Monthly Variability and Worst month distribution for 2017 Rain rate Measurements

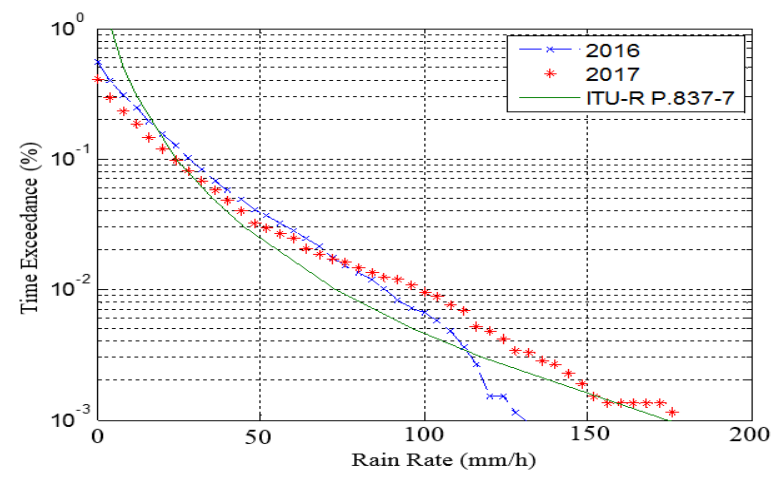

Figure 7. Complementary cumulative distribution function (CCDF) of Rainfall Rate for 2016 and 2017 Measurements and ITU-R P. 837-7 Prediction for Abuja 


\subsection{Induced Rain Attenuation on $6 \mathrm{MHz}$ and $2 \mathrm{MHz}$ RF Bandwidth}

The relationship between allocated bandwidth and carrier power for a given threshold of performance shows that the carrier to noise ratio must be defined for expected throughput. This can be effectively achieve when optimization is considered for power and bandwidth. Therefore the carrier parameters should be considered instead of only increasing demands for bandwidth. Figure 8 and Figure 9 shows the received signals during clear sky and rain induced effects respectively. The induced rain attenuation results in the carrier power loss of $27.4 \mathrm{~dB}$ due to rain effect as sampled on the $30^{\text {th }}$ day of May 2018 at 4:34 pm Abuja Nigeria local time. The loss from $34.50 d B$ to $7.10 d B$ occurred just 5-minutes into the rain events. The carrier to noise ratio $(\mathrm{CNR})$ or $\mathrm{C} / \mathrm{N}$ determines the quality of signal above the noise for demodulation of the information at the receiver. When the signal attenuation is increased the signal becomes similar to noise resulting in spread spectrum effect which may not be demodulated by the receiver modem. This loss is happening concurrently as the rain intensity exceeds $50 \mathrm{~mm} / \mathrm{h}$.

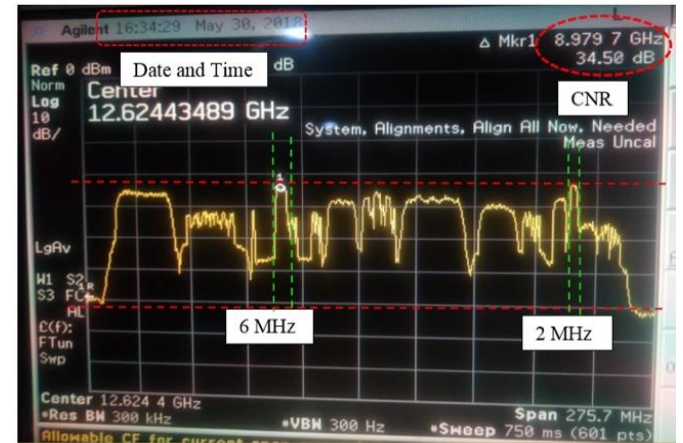

Figure 8. Clear sky Broadband Signal $(\Delta 1)$ with CNR of $34.50 \mathrm{~dB}$ on 30th May, 2018 in Clear Sky

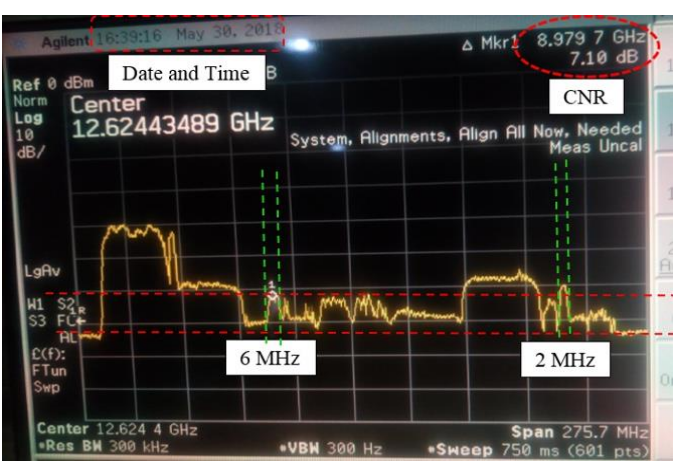

Figure 9. Sample of Broadband Signal $(\Delta 1)$ affected by Rain with CNR of $7.10 \mathrm{~dB}$ on May 30 2018

Figure 10 and Figure 11 presents the allocated bandwidths of $2 \mathrm{MHz}$ and $6 \mathrm{MHz}$ capacity including overhead and guard bands with constant $\mathrm{C} / \mathrm{N}$ minimum thresholds of $6 \mathrm{~dB}$. The bandwidth utilizations at higher $\mathrm{C} / \mathrm{N}$ was low for both $2 \mathrm{MHz}$ and $6 \mathrm{MHz}$ capacity. The type of modulation adopted and the forward error correction coding are among the factors influencing the performance not just the bandwidth. At higher power a lower occupied bandwidth was utilized. This is one of the advantage achievable in bandwidth sharing and adaptive scheme in satellite communication. Therefore the quest for more bandwidth to achieve higher data rate by the satellite service users may not always hold. Narrow bandwidth on the other hand tend to exhibit higher gain due to its lower noise bandwidth, therefore with optimized modulation and coding rate can deliver high data rate for certain quality of service requirements provided the carrier to noise ratio is above the threshold of performance. The $2 \mathrm{MHz}$ allocated bandwidth in Figure 11 shows a better stability and performance of power to bandwidth relationship when compared to the $6 \mathrm{MHz}$ bandwidth of Figure 10. With advancements in modulation technique the quest for more bandwidth and higher operating frequency may be reconsidered. Reduced coverage size and multiple spot beams can be an option to deliver higher data rate requirements.

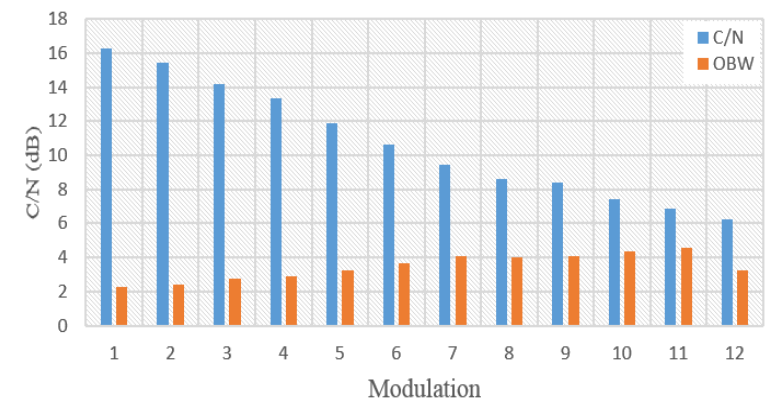

Figure 10. Power and Bandwidth of $6 \mathrm{MHz}$

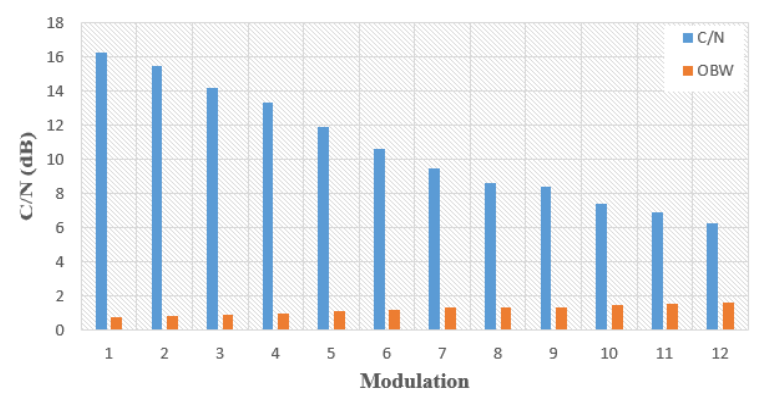

Figure 11. Power and Bandwidth of $2 \mathrm{MHz}$ 


\section{CONCLUSION}

Rain attenuation and random variability from month to month and annual rainfall trend calls for more real-time approach to link outage and carrier performance due to the fact that the higher frequencies are continuously vulnerable. For constant quality of service, the carrier to noise ratio must be above any design threshold level relative to the allocated bandwidth. This shows that the RF carrier power above the noise level can guarantee the quality of service irrespective of the bandwidth allocated due to the relative noise bandwidth. Satellite transponders operating multiple carrier per channel may be subjected to adjacent channel interference and induced noise attenuation from several sources including thermal noise, side lobe and adjacent satellite coverage overlap. The huge variability in rainfall from year to year and the worst month is of critical concern. This can adversely affect the design and performance of any satellite link especially for tropical rain regions. This study further presents the dependence of link performance on the carrier power above the system noise level. Therefore the quest for high frequency to allow for higher bandwidth capacity to meet the user's demand need to be reconsidered in terms of power rather than bandwidth. Increased RF bandwidth at constant carrier level can only improve the broadband throughput by about $20 \%$ while increasing the carrier power result in about $80 \%$ improvement due to the controlled bandwidth noise. This study further recommend for improvement the quality of uplink station equipments, transponder noise reduction and improve high power amplifier again to allow for thermal noise control and improve the overall carrier power to noise ratio.

\section{ACKNOWLEDGEMENTS}

This work has been funded by Ministry of Education Malaysia with Universiti Teknologi Malaysia under HICOE University Grant Vot. No. 4J221, FRGS Vot. No. 4F958 and the Universiti Tun Hussein Onn Malaysia under research grant Vot H160, and was partially developed in the framework of the Universiti Teknologi Malaysia Contract Research, Vot. No. 4C062.

\section{REFERENCES}

[1] F. Cuervo, et al, "Ka-band propagation campaign in Malaysia-First months of operation and site diversity analysis," 10th European Conference on Antennas and Propagation, Davos, 2016, pp. 1-5.

[2] T.V. Omotosho and C.O. Oluwafem "Impairment of radio wave signal by rainfall on fixed satellite service on earth-space path at 37 stations in Nigeria". Journal of Atmospheric and Solar-Terrestrial Physics 712009.

[3] Ippolito, L. Jr. "Satellite Communications Systems Engineering: Atmospheric Effects, Satellite Link Design and System Performance". (1st edition.) UK: John Wiley, 2008.

[4] Teresa M. Braun, "Satellite communications payload and system" ( $1{ }^{\text {st }}$ Edidition) ISBN-13:978-0470540848, 2012.

[5] Selvachandran Kogulan "Influence of weather on Beacon power level, 2015. www.sourceforge.isae.fr/projects

[6] R. Monjo and J. Martin-Vide "Daily precipitation concentrated around the world". International Journal of Climatology, willey online Library, 2016.

[7] American Meteorological Society, 2014 global precipitation report 2014. www.journals.ametsoc.org

[8] Mandeep J.S et al, "Analysis of worst-month relationship with annual rain attenuation in Malaysia" Journal of applied Science, Engineering and Technology: 1453-1455, 2014.

[9] O. M. Durodola, et al, "Characterization of Worst Month Statistics for Satellite-Earth Links Performance Tropical Locations". Physical Science International Journal 13(3): 1-9, 2017; Article no.PSIJ.31899.

[10] S. C. K. Lye, et al, "Performance of Signal-to-Noise Ratio Estimator with Adaptive Modulation," 2012 Sixth Asia Modelling Symposium, Bali, pp. 215-219 2012.

[11] O. O. Obiyemi, et al, "Rainfall variability and impact on Communication Infrastructure in Nigeria" Journal of Telecommunications, vol.25 issue 1, may, 2014.

[12] Jong, S.L., et al " Analysis of fade dynamic at Ku-Band in Malaysia " International Journal of Antennas and Propagation ", Vol 1, 2014.

[13] R. J. Colby, et al "An introduction to testing techniques in the intelsat TDMA/DSI system". Part 3: Specialized test equipment for ssog tests, International Journal of Satellite Communications, 2, 3, (145-159), 2006.

[14] J. S. Mandeep, et al "Rainfall effect on Ku-band satellite link design in rainy Tropical Climate" Journal of Geographical Research", vol. 113, 2008.

[15] D. Giggenbach, E. et al, "A High-Throughput Satellite System for Serving whole Europe with Fast Internet Service, Employing Optical Feeder Links," Broadband Coverage in Germany. 9th ITG Symposium. Proceedings, Berlin, Germany, pp. 1-7 2015.

[16] ITU-R "Propagation data and prediction methods required for the design of Earth-Space telecommunication system”. P Series Geneva, Switzerland: International Telecommunication Union P.618-12, 2015.

[17] Kvicera V., et al, "Comparing of Tipping Bucket Rain Gauge Record Processing at Various Workplace". 3rd Int. Workshop of the COST280 Action 'Propagation Impairments Mitigation f o r Millimetre-Wave Radio Systems, 2005 . 


\section{BIOGRAPHIES OF AUTHORS}
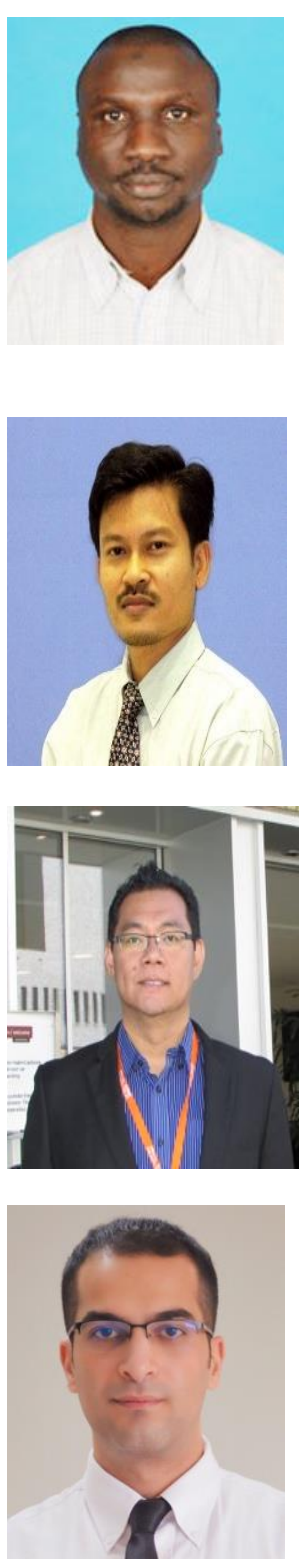

Idrissa Abubakar, Obtained (B.Eng) - Degree in Electrical \& Electronics, University of Maiduguri, Nigeria 2001. Postgraduate Certificate in Space System \& Communication Satellite Payload, from China Academy of Space Technology (CAST), Shenzhou Institute, Beijing, 2007. Master of Engineering Degree (M.Eng) in Electronic and Information Engineering, Beihang University, Beijing China, 20012. Research study in Space to Earth Satellite Propagation under the supervision of Prof. Madya Dr. Jafri Din. Worked at Nigerian National Space Research and Development Agency, Abuja. Currently working with Network Operations Center and Satellite Applications Division of Nigerian Communications Satellite (NigComSat) Ltd, Also worked with as field engineer with InterC Network Nigeria PLC, a Mobile/Fixed Wireless Telecommunications Company offering both GSM and CDMA wireless services in Nigeria.

Prof. Dr. Jafri Bin Din received his BSEE in Electrical Engineering from Tri-State University, Indiana USA in 1988 and his Ph.D from Universiti Teknologi Malaysia, Johor, Malaysia in 1997. He has been Head of Departments, Undergraduate Academic Manager Deputy Dean (Development) in Faculty of Electrical Engineering (FKE) UTM from 2008 till 2013. He is currently the Deputy Director of Wireless Communication Center (WCC) UTM. His research activities have been correlated to the field of radio wave propagation, satellite propagation and communications, High Altitude platform stations (HAPS), Satellite TV broadcasting, Weather Radar and sound technique for fisheries Industry.

Hong Yin Lam received the M. Eng. and the Ph.D. degrees in electrical engineering and telecommunication from the Universiti Teknologi Malaysia (UTM), Johor, Malaysia, in 2009 and 2013, respectively. He then served as a postdoctoral fellow in the Department of Communication Engineering (UTM), Johor, Malaysia. He is currently a lecturer at Faculty of Engineering Technology, Universiti Tun Hussein Onn, Malaysia, since 2007. His research activities have been relative to the field of radio wave propagation through the atmosphere, with specific focus on rain (rain drop size distribution and structures characterization) for propagation applications. Lam is a recipient of the Young Scientist Awards at the International Symposium on Antennas and Propagation (ISAP), Japan, in 2012, and Asia Pacific Radio Science Conference, Taiwan, in 2013.

Manhal Alhilali received the B.Sc. in Electrical and Electronics Engineering from Omar AlMukhtar University, Albayda', Libya in 2010, M. Eng. and Ph.D. degrees in electrical, electronics, and telecommunications from the Universiti Teknologi Malaysia (UTM), Johor, Malaysia, in 2014 and 2018, respectively. His research activities are related to the field of electromagnetic wave propagation through the atmosphere; physical and statistical modeling for electromagnetic propagation applications; analysis of wireless terrestrial 5G links operating in the 10 to100 $\mathrm{GHz}$ range; design and simulation of wireless communication systems implementing fade mitigation techniques; tropical meteorology; remote sensing; and antenna design. Manhal is a Member of the Institute of Electrical and Electronic Engineering (IEEE), IEEE APS, IEEE COMSOC, and the American Geophysical Union. 